\title{
CALIBRATING THE PASSENGER CAR EQUIVALENT ON ITALIAN TWO LINE HIGHWAYS: A CASE STUDY
}

\author{
Mario De Luca, Gianluca Dell'Acqua \\ University of Napoli 'Federico II', Via Claudio 21, I-80125 Napoli, Italy
}

Submitted 12 June 2013; accepted 2 September 2013; first published online 16 October 2013

\begin{abstract}
The Level Of Service (LOS) of a road infrastructure, a concept introduced for the first time in the Highway Capacity Manual (second edition), is defined as the 'qualitative measure of traffic conditions and their perception by users'. The Highway Capacity Manual, developed in the U.S., is still the most highly internationally credited reference text in the study of vehicular traffic. The method proposed by the Highway Capacity Manual is based mainly on studies and research compiled in the U.S., so in order to apply this method to other realities (e.g. Italy), research needs to be carried out at a local level. In this study, a series of studies were carried out to verify the transferability of these procedures to two roads classified as 'two-lane highways'. Two fixed RTMS (Remote Traffic Microwave Sensor) were used to record traffic data for two sections located at $3100 \mathrm{~km}$ on the SP30 and at $8900 \mathrm{~km}$ on the SP175 from 1 January to 31 December 2010. From the data, it was possible to determine not only the relationships between the basic parameters of the traffic flow, but also the (Passenger Car Equivalent) (PCE) values. The results showed that the PCEs analyzed vary significantly with vehicular flow, while they are scarcely affected by changes in speed. In particular, with respect to the vehicular flow, although they have the same range recorded in the Highway Capacity Manual (2010) (between 1 and 2), they tend to be higher than those given in the manual, and the difference tends to diminish beyond a flow rate of $400 \div 450$ pcphpl; the PCE coefficients also tend towards 1 (i.e., the condition where a heavy vehicle is comparable to a car) with range values approaching $1000 \mathrm{pcphpl}$. In addition, for these values, the traffic-flow diagrams obtained, showed speeds (defined as the critical speed) close to $50 \div 55 \mathrm{~km} / \mathrm{h}$ (with the exception of the study conducted on the SP175 in direction $d 2$, which is considerably higher).
\end{abstract}

Keywords: traffic flow, passenger car equivalent (PCE), level of service (LOS), speed, density.

\section{Introduction and Previous Research}

The Level Of Service (LOS) of a road infrastructure, a concept introduced for the first time in the second edition of the Highway Capacity Manual (2010), is defined as a 'qualitative measure of traffic conditions and their perception by users'. The Highway Capacity Manual, developed in the U.S., is still the most highly internationally credited reference text in the study of vehicular traffic. The procedure for calculating the LOS, described in this manual, makes it possible to assign a rating for the quality of traffic flow through the application of specific procedures. In particular, it establishes the conditions and the criteria established to apply the proposed procedures. These conditions, referred to as 'base conditions' are the road's geometry, the traffic conditions on the road, and the environmental context through which the road passes.

The basic conditions include one relating to the composition of the traffic flow that considers only pas- senger cars in the flow of traffic. Therefore, the concept of equivalence between heavy vehicles and passenger cars is introduced through the special coefficients indicated by the acronym PCE (Passenger Car Equivalent). These coefficients, however, if they are not too approximate, must be obtained experimentally, as specifically recommended by the Highway Capacity Manual, in the local area. The study recommends (declaring the approximate nature of the results) using values obtained in research carried out on the U.S. territory as equivalents (PCE coefficients) only in the absence of specific local indications. Since 1965, the estimated equivalent, and especially the definition of methods of calculation has been the subject of many international researches. The former is based on an assessment of the overtaking rate (number of overtakes per $\mathrm{km}$ ) and the delays caused to cars by heavy goods vehicles before they could complete the overtaking maneuver.

The limits of applicability of these methods were overcome in the $80 \mathrm{~s}$. On this subject, the research of 
Linzer et al. (1979) and Huber (1982) may be cited. These authors were among the first to introduce the calculation of the PCE on the basis of the comparison of a defined basis flow (consisting of only cars) and a mixed flow (consisting of both cars and heavy vehicles) which determined the level of impedance on the traffic flow. The authors defined this impedance as any measure capable of quantifying the restrictive effects on traffic flow compared with the flow in question.

Subsequently, many authors, such as Cunagin and Messer (1983), Van Aerde and Yagar (1984), and Elefteriadou et al. (1997), while continuing to share the basic philosophy of the method, suggested other impedance measurements, such as density and/or the Volume/Capacity $(V / C)$ ratio. Then, additional methods were introduced which, while based on the same impedance measurements, led to some important variations.

In this regard, Chandra et al. (1995) is worthy of mention. According to Chandra, calculation of the equivalent is based on the relationship between the speed ratio (measuring the impedance representative of the traffic conditions) and the space ratio (representative of the performance characteristics of vehicles). An important criticism regarding the use of PCE for conditions of forced flow (beyond capacity), and in particular in the dispersal of a queue has been raised by Al-Kaisy et al. (2002).

According to Al-Kaisy et al. (2002), the use of PCE in the above traffic conditions underestimates the effects of the presence of heavy vehicles in the flow, since no account is taken of the reduced performance in terms of acceleration and deceleration that heavy-duty vehicles produce under 'stop and go' conditions (typical traffic conditions beyond capacity). All calculation methods identify the PCE based on the range, length and grade of the vertical alignment and the type of heavy vehicles in circulation. These correspondences have been confirmed in numerous scientific papers related to applications to case studies conducted in contexts different from those studied as a basis for the calculation methods, aiming to test the transferability of the methods themselves.

Examples include applications in China (Fan 1990), Canada (Sun et al. 2008) and a more recent one developed and introduced in Brazil (Cunha, Setti 2011), etc.

Other important studies have been conducted by Werner and Morrall (1976), who have adopted the temporal spacing method for calculating the PCE of vehicles traveling at a low speed and the impedance method for heavy vehicles traveling at a high speed.

Similarly Krammes and Crowley (1986) conclude in one of their articles that the spatial distancing method not only takes into account the impact of heavy vehicles in terms of size and performance, but also the psychological impact on the drivers of other vehicles. This impact, for example, manifests itself in the form of aerodynamic disturbance, spray and splashing in rainy conditions, and the obstruction of the visibility of road signs. Lastly, in another important relationship (Webster, Elefteriadou 1999) regarding highway traffic (where simulation models were used to calculate the correlation between flow and density) the correspondence between PCE and the flow of traffic is calculated, taking into consideration the percentage of heavy vehicles in the flow, the type of heavy vehicle, the length and grade of the vertical alignment, and the number of lanes.

\section{The Data Set and Data Processing}

\subsection{Survey of Data}

The traffic data were collected on two different roads located in the south of Italy (Dell'Acqua et al. 2011): the Eboli-Mare SP30 and the Salerno-Paestum SP175 (Fig. 1).

Both roads are classified as 'two-lane highways', level terrain, without posted speed limit, Annual Average Daily Traffic (AADT) 13000 veh/day (SP30) and $15000 \mathrm{veh} /$ day (SP175), 1 access per $\mathrm{km}$, long distance (in terms of prevailing trips), dense asphalt carriageway characterized by lanes $3.50 \mathrm{~m}$ wide and a shoulder width of $1.5 \mathrm{~m}$. The traffic data were obtained using two fixed Remote Traffic Microwave Sensor (RTMS) devices that collect the data continuously (Fig. 2). The two continuous traffic detection devices were placed (in a fixed location) in two sections, located at distance $3100 \mathrm{~m}$ on the SP30, and at the distance $8900 \mathrm{~m}$ on the SP175, from 1 January to 31 December 2010.

The Electronic Integrated Systems Inc. (EIS, Ontario, Canada) radar antenna is made up of the following main elements:

- RTMS traffic analyzer Model K3;

- RTC (Remote Traffic Counter) Data storage unit;

- GSM Terminal Module MC35T.

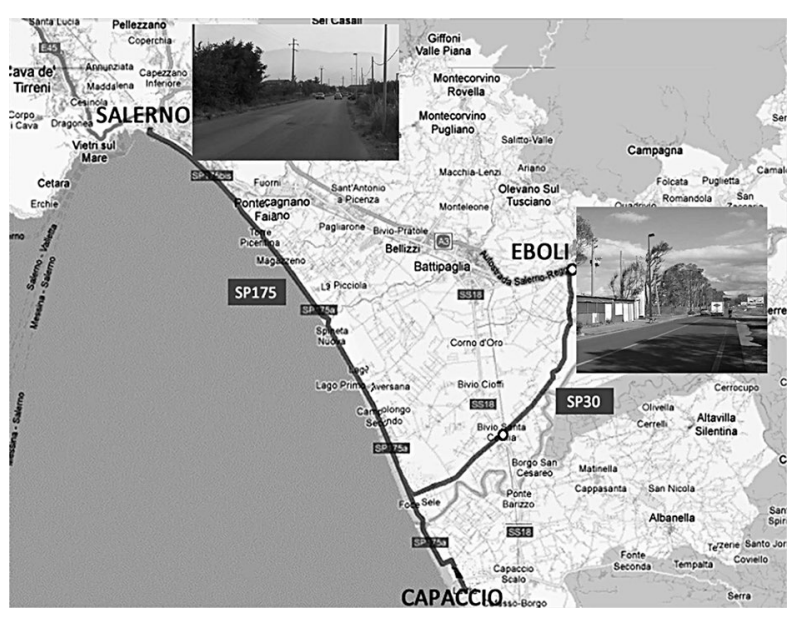

Fig. 1. Analyzed roads: SP175 and SP30

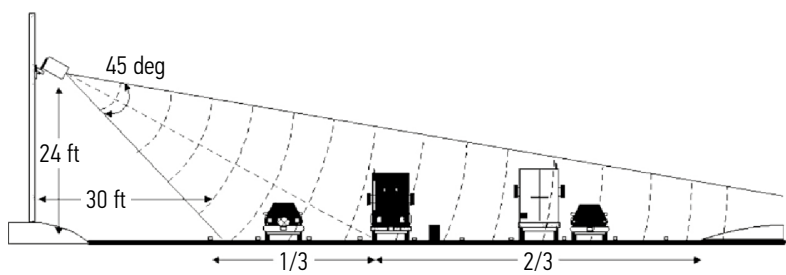

Fig. 2. RTMS aiming 
These devices work by the emission and subsequent reception of microwaves, i.e. high frequency electromagnetic radiation with a wavelength between that of radio waves and that of infrared radiation.

Traffic data were collected continuously, in every kind of weather condition (sun, rain or fog), recording the number of vehicles passing by, the percentage of occupants, the type of vehicles divided into six classes (depending on length) and the average speed. The data collected on both traffic lanes are stored on the hard drive every minute and transmitted daily to the server through the GSM connection module network.

\subsection{Data Collection}

The data collected in dry pavement conditions (in the Highway Capacity Manual (2010), all the procedures are referred to dry pavement) using the system described in the previous paragraph have been organized into two different databases, one for each road.

The first consists of about 500000 records and the second about 225000 records; the data have been organized into intervals with an range of 1 minute for 6 different classes of vehicle according to the average length of the vehicles (Table 1 ) in two different directions $d 1$ and $d 2$. Tables 1 and 2 show the structure of the database used to organize the data.

The first step was to determine, on the basis of the experimental data reported in Table 1, the equivalent in passenger cars (necessary to convert the volume into flow rate) and then the relationships between the traffic flow parameter, i.e. speed, density and traffic volume.

\section{Calibrating PCE}

The method proposed by Huber (1982) to calculate the PCE, was used. This method is based on the following
Table 2. Symbols and units of used variables

\begin{tabular}{clc}
\hline Vehicle category & \multicolumn{1}{c}{ Description } & Average length $[\mathrm{m}]$ \\
\hline SM & Small & $L<5$ \\
\hline MS1 & Midsize & $5<L<7$ \\
\hline MS2 & Midsize & $7<L<10$ \\
\hline LV1 & Long Vehicle 1 & $10<L<15$ \\
\hline LV2 & Long Vehicle 2 & $15<L<20$ \\
\hline XLV & Extralong Vehicle: & $L>20$ \\
\hline
\end{tabular}

hypothesis: given the first interval $i$ (equal to 1 minute) consisting only of cars, indicated as $Q_{B}$, with an average speed indicated as $S B$ and expressed in $\mathrm{km} / \mathrm{h}$ and given the second interval $j$ (equal to 1 minute) consisting of $Q_{C}$ passenger cars and $Q_{H}$ heavy vehicles, with an average speed indicated as $S C$ and expressed in $\mathrm{km} / \mathrm{h}$ :

$$
\begin{aligned}
& \text { if } Q_{B} \geq\left(Q_{c}+Q_{H}\right) \text { and } S B=S C \text { then: } \\
& Q_{B}=Q_{c}+P C E \cdot Q_{H},
\end{aligned}
$$

where: $Q_{B}$ (expressed in veh/h) is the 'flow base', the part of the flow for the interval $i$ made up of cars only and always belongs to the category of vehicles $S M(L<5 \mathrm{~m})$; $Q_{C}$ (expressed in veh/h) is the part of the flow for the interval $j$ consisting of only passenger cars always belonging to the category of vehicles $S M(L<5 \mathrm{~m}) ; Q_{H}$ (expressed in veh/h) is the part of the flow for the interval $j$ consisting of only heavy vehicles and always belonging to the category of vehicles other than $S M$ (with $L>5 \mathrm{~m}$ ); $P C E$ is the equivalence coefficient between heavy vehicles and passenger cars.

The PCEs were calculated for both roads in both directions, differentiated according to class both on the

\begin{tabular}{|c|c|c|c|c|c|c|c|c|c|c|c|c|c|c|c|c|c|}
\hline Data & Minute & $\begin{array}{c}\text { N. veh. } \\
d 1\end{array}$ & $\begin{array}{c}\text { N. veh. } \\
d 2\end{array}$ & $\begin{array}{l}\mathrm{SM} \\
d 1\end{array}$ & $\begin{array}{l}\mathrm{SM} \\
d 2\end{array}$ & $\begin{array}{c}\text { MS1 } \\
d 1\end{array}$ & $\begin{array}{c}\text { MS1 } \\
d 2\end{array}$ & $\begin{array}{c}\text { MS2 } \\
d 1\end{array}$ & $\begin{array}{c}\text { MS2 } \\
d 2\end{array}$ & $\begin{array}{l}\mathrm{LV} 1 \\
d 1\end{array}$ & $\begin{array}{l}\mathrm{LV} 1 \\
d 2\end{array}$ & $\begin{array}{c}\mathrm{LV} 2 \\
d 1\end{array}$ & $\begin{array}{l}\text { LV2 } \\
d 2\end{array}$ & $\begin{array}{c}\text { XLV } \\
d 1\end{array}$ & $\begin{array}{c}\text { XLV } \\
d 2\end{array}$ & $\begin{array}{l}\text { Speed } d 1 \\
{[\mathrm{~km} / \mathrm{h}]}\end{array}$ & $\begin{array}{c}\text { Speed } d 2 \\
{[\mathrm{~km} / \mathrm{h}]}\end{array}$ \\
\hline 1 January 2010 & 0 & 5 & 6 & 4 & 4 & 0 & 1 & 0 & 0 & 0 & 0 & 0 & 1 & 1 & 0 & 50 & 41 \\
\hline 1 January 2010 & 1 & 2 & 5 & 2 & 2 & 0 & 1 & 0 & 0 & 0 & 0 & 0 & 0 & 0 & 2 & 51 & 44 \\
\hline 1 January 2010 & 2 & 4 & 6 & 4 & 4 & 0 & 2 & 0 & 0 & 0 & 0 & 0 & 0 & 0 & 0 & 54 & 50 \\
\hline 1 January 2010 & 3 & 5 & 9 & 5 & 6 & 0 & 2 & 0 & 1 & 0 & 0 & 0 & 0 & 0 & 0 & 58 & 54 \\
\hline 1 January 2010 & 4 & 6 & 5 & 4 & 3 & 0 & 2 & 1 & 0 & 0 & 0 & 0 & 0 & 1 & 0 & 62 & 55 \\
\hline 1 January 2010 & 5 & 6 & 8 & 4 & 1 & 0 & 1 & 0 & 1 & 0 & 2 & 0 & 1 & 2 & 2 & 38 & 59 \\
\hline 1 January 2010 & 6 & 4 & 8 & 4 & 2 & 0 & 4 & 0 & 1 & 0 & 0 & 0 & 0 & 0 & 1 & 62 & 59 \\
\hline 1 January 2010 & 7 & 7 & 6 & 5 & 1 & 0 & 3 & 0 & 2 & 0 & 0 & 1 & 0 & 1 & 0 & 62 & 59 \\
\hline 1 January 2010 & 8 & 1 & 5 & 1 & 1 & 0 & 4 & 0 & 0 & 0 & 0 & 0 & 0 & 0 & 0 & 62 & 58 \\
\hline 1 January 2010 & 9 & 6 & 7 & 2 & 1 & 1 & 2 & 0 & 1 & 0 & 1 & 0 & 1 & 3 & 1 & 53 & 58 \\
\hline 1 January 2010 & 10 & 1 & 7 & 0 & 3 & 0 & 2 & 0 & 0 & 0 & 0 & 0 & 1 & 1 & 1 & 61 & 60 \\
\hline 1 January 2010 & 11 & 4 & 9 & 4 & 4 & 0 & 3 & 0 & 2 & 0 & 0 & 0 & 0 & 0 & 0 & 61 & 61 \\
\hline 1 January 2010 & 12 & 3 & 4 & 3 & 2 & 0 & 1 & 0 & 1 & 0 & 0 & 0 & 0 & 0 & 0 & 61 & 63 \\
\hline 1 January 2010 & 13 & 7 & 6 & 3 & 1 & 0 & 1 & 1 & 2 & 0 & 1 & 0 & 0 & 3 & 1 & 62 & 64 \\
\hline$\ldots$ & $\ldots$ & $\cdots$ & $\cdots$ & $\ldots$ & $\ldots$ & $\ldots$ & $\ldots$ & $\ldots$ & $\ldots$ & $\ldots$ & $\ldots$ & $\ldots$ & $\ldots$ & $\cdots$ & $\ldots$ & $\ldots$ & $\ldots$ \\
\hline 31 December 2010 & 60 & 1 & 1 & 1 & 1 & 0 & 0 & 0 & 0 & 0 & 0 & 0 & 0 & 0 & 0 & 70 & 58 \\
\hline
\end{tabular}

Table 1. Organization of data 
basis of the different classes of volume and different categories of speed (Fig. 3). For example, to calculate the PCE (for the category 'MS1'), the category 'SM' as a set containing only cars was used, and the category 'MS1' as a set containing cars and trucks. Similarly for the category 'MS2', the category 'SM' as a set containing only cars was used, and the category 'MS2' as a set containing cars and trucks. This procedure was repeated for all the categories of vehicles indicated in Table 3 . This operation resulted in a total analysis of 3800 different combinations of the different variables in the system.

Given the complexity of calculating all these operations, the second algorithm was implemented that specifically made it possible to find in a reasonable time all the ranges that met all the conditions imposed by the above presented relations.

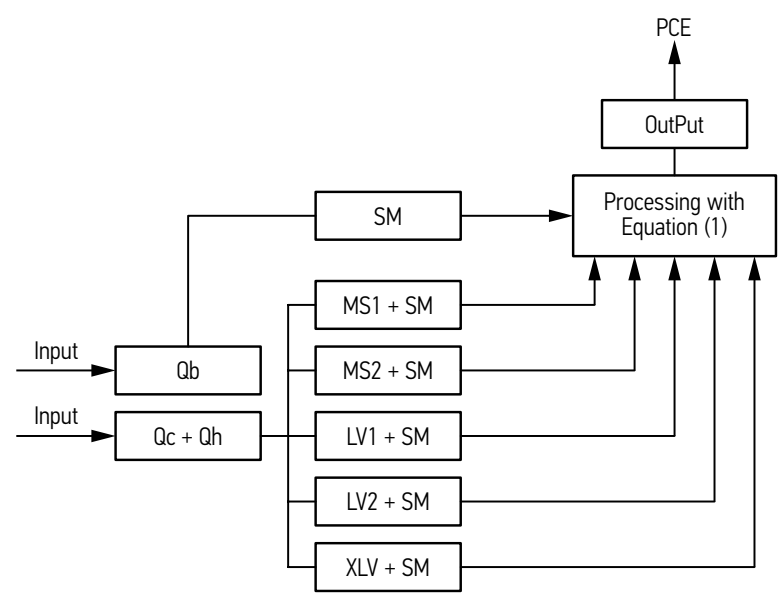

Fig. 3. Logical framework for the selection of the ranges
From the performed calculations, it emerged that the PCE coefficients have low variability when speeds vary, while there is considerable volume-dependent variability.

Table 3 and Fig. 4 show the results obtained. In particular, they show the PCE values for the two roads analyzed when the volume varies.

Fig. 4 shows the same results in graphic form. From these, the tendency of the PCE to decrease with increasing 'traffic volume' is immediately apparent. It should be noted that the PCE, in agreement with the Highway Capacity Manual (2010), reaches a lower limit value (equal to 1) for volume of about $1000 \mathrm{veh} / \mathrm{h} / \mathrm{ln}$. This particular aspect is due to the fact that in these conditions the heavy vehicle can be considered similar to a car. Furthermore, with these values of volume, using the diagrams ' $S-V$ ' shown in Figs 5 and 6, it is possible to identify the critical speed at which the PCE is 1. For this reason, for SP30 this critical speed was identified for both directions $d 1$ and $d 2$ at around $50 \mathrm{~km} / \mathrm{h}$; for the SP175 this value is significantly higher in direction $d 1$ (about $65 \mathrm{~km} / \mathrm{h}$, due to a lower presence of heavy vehicles), while it is around $55 \mathrm{~km} / \mathrm{h}$ in direction $d 2$.

\section{Traffic Flow Parameters}

By processing the data shown in Table 1, it was possible to define, for both roads and for each direction, the relations between the fundamental traffic flow parameter, i.e.:

- traffic volume - $V$;

- speed - $S$;

- density - $D$.

In particular, so that to construct these reports it was necessary to transform the 'traffic volume' into the

Table 3. PCE for SP30 road, directions $d 1$ and $d 2$

\begin{tabular}{c|ccccc|ccccc}
\hline \multirow{2}{*}{$q[\mathrm{veh} / \mathrm{h} / \mathrm{ln}]$} & \multicolumn{6}{|c|}{ Direction $d 1$} & \multicolumn{5}{c}{ Direction $d 2$} \\
\cline { 2 - 11 } & $\mathrm{PCE}_{\mathrm{MS} 1}$ & $\mathrm{PPCE}_{\mathrm{MS} 2}$ & $\mathrm{PPCE}_{\mathrm{LV} 1}$ & $\mathrm{PPCE}_{\mathrm{LV} 2}$ & $\mathrm{PCE}_{\mathrm{XLV}}$ & PPCE $_{\mathrm{MS} 1}$ & PCE $_{\mathrm{MS} 2}$ & PPCE $_{\mathrm{LV} 1}$ & PPCE $_{\mathrm{LV} 2}$ & $\mathrm{PCE}_{\mathrm{XLV}}$ \\
\hline$\leq 120$ & 2.00 & 2.00 & 2.00 & 2.00 & 2.00 & 2.00 & 2.00 & 2.00 & 2.00 & 2.00 \\
\hline 180 & 1.91 & 1.98 & 1.98 & 2.00 & 2.00 & 1.71 & 1.77 & 1.82 & 1.72 & 1.73 \\
\hline 240 & 1.87 & 1.95 & 1.97 & 1.99 & 1.99 & 1.66 & 1.74 & 1.77 & 1.74 & 1.75 \\
\hline 300 & 1.88 & 1.89 & 1.94 & 1.96 & 2.00 & 1.55 & 1.54 & 1.54 & 1.55 & 1.63 \\
\hline 360 & 1.79 & 1.87 & 1.92 & 1.98 & 1.95 & 1.54 & 1.54 & 1.53 & 1.57 & 1.64 \\
\hline 420 & 1.75 & 1.80 & 1.78 & 1.81 & 1.87 & 1.54 & 1.54 & 1.53 & 1.52 & 1.55 \\
\hline 480 & 1.72 & 1.78 & 1.79 & 1.77 & 1.87 & 1.42 & 1.51 & 1.51 & 1.45 & 1.64 \\
\hline 540 & 1.59 & 1.59 & 1.60 & 1.61 & 1.66 & 1.44 & 1.44 & 1.46 & 1.47 & 1.47 \\
\hline 600 & 1.52 & 1.52 & 1.56 & 1.57 & 1.61 & 1.35 & 1.36 & 1.35 & 1.36 & 1.45 \\
\hline 660 & 1.44 & 1.45 & 1.37 & 1.45 & 1.54 & 1.22 & 1.22 & 1.33 & 1.34 & 1.43 \\
\hline 720 & 1.30 & 1.31 & 1.42 & 1.43 & 1.45 & 1.10 & 1.11 & 1.11 & 1.11 & 1.32 \\
\hline 780 & 1.24 & 1.27 & 1.32 & 1.33 & 1.33 & 1.13 & 1.15 & 1.11 & 1.11 & 1.11 \\
\hline 840 & 1.23 & 1.31 & 1.31 & 1.31 & 1.31 & 1.13 & 1.10 & 1.11 & 1.10 & 1.10 \\
\hline 900 & 1.09 & 1.09 & 1.09 & 1.11 & 1.15 & 1.00 & 1.00 & 1.00 & 1.00 & 1.00 \\
\hline 960 & 1.00 & 1.03 & 1.06 & 1.06 & 1.12 & 1.00 & 1.00 & 1.01 & 1.00 & 1.00 \\
\hline 1020 & 1.00 & 1.00 & 1.00 & 1.00 & 1.07 & 1.00 & 1.00 & 1.00 & 1.00 & 1.00 \\
\hline$\geq 1080$ & 1.00 & 1.00 & 1.00 & 1.00 & 1.00 & 1.00 & 1.00 & 1.00 & 1.00 & 1.00 \\
\hline & & & & & & & & & \\
\hline
\end{tabular}


Table 4. PCE for SP175 road, directions $d 1$ and $d 2$

\begin{tabular}{c|ccccc|ccccc}
\hline \multirow{2}{*}{$q[\mathrm{veh} / \mathrm{h} / \mathrm{ln}]$} & \multicolumn{5}{|c}{ Direction $d 1$} & \multicolumn{5}{c}{ Direction $d 2$} \\
\cline { 2 - 11 } & $\mathrm{PPCE}_{\mathrm{MS} 1}$ & $\mathrm{PPCE}_{\mathrm{MS} 2}$ & $\mathrm{PPCE}_{\mathrm{LV} 1}$ & $\mathrm{PPCE}_{\mathrm{LV} 2}$ & $\mathrm{PCE}_{\mathrm{XLV}}$ & PPCE $_{\mathrm{MS} 1}$ & PCE $_{\mathrm{MS} 2}$ & PPCE $_{\mathrm{LV} 1}$ & PPCE $_{\mathrm{LV} 2}$ & PCE $_{\mathrm{XLV}}$ \\
\hline$\leq 120$ & 2.00 & 2.00 & 2.00 & 2.00 & 2.00 & 2.00 & 2.00 & 2.00 & 2.00 & 2.00 \\
\hline 180 & 1.96 & 1.96 & 1.99 & 2.00 & 2.00 & 1.95 & 1.91 & 1.97 & 2.00 & 2.00 \\
\hline 240 & 1.81 & 1.94 & 1.97 & 1.99 & 1.99 & 1.79 & 1.94 & 1.98 & 2.00 & 1.99 \\
\hline 300 & 1.68 & 1.87 & 1.88 & 1.97 & 1.97 & 1.78 & 1.84 & 1.85 & 1.94 & 1.94 \\
\hline 360 & 1.64 & 1.79 & 1.79 & 1.88 & 1.87 & 1.75 & 1.76 & 1.76 & 1.82 & 1.84 \\
\hline 420 & 1.51 & 1.75 & 1.74 & 1.77 & 1.80 & 1.55 & 1.70 & 1.71 & 1.74 & 1.77 \\
\hline 480 & 1.47 & 1.63 & 1.70 & 1.70 & 1.70 & 1.46 & 1.60 & 1.67 & 1.67 & 1.67 \\
\hline 540 & 1.50 & 1.57 & 1.58 & 1.61 & 1.61 & 1.52 & 1.58 & 1.55 & 1.57 & 1.58 \\
\hline 600 & 1.49 & 1.58 & 1.59 & 1.61 & 1.62 & 1.43 & 1.59 & 1.60 & 1.61 & 1.62 \\
\hline 660 & 1.46 & 1.49 & 1.50 & 1.50 & 1.57 & 1.45 & 1.49 & 1.50 & 1.51 & 1.52 \\
\hline 720 & 1.38 & 1.45 & 1.42 & 1.42 & 1.52 & 1.34 & 1.43 & 1.42 & 1.42 & 1.52 \\
\hline 780 & 1.22 & 1.25 & 1.24 & 1.25 & 1.41 & 1.25 & 1.26 & 1.26 & 1.27 & 1.42 \\
\hline 840 & 1.24 & 1.27 & 1.33 & 1.33 & 1.38 & 1.25 & 1.24 & 1.33 & 1.34 & 1.38 \\
\hline 900 & 1.19 & 1.23 & 1.24 & 1.29 & 1.26 & 1.19 & 1.24 & 1.25 & 1.30 & 1.26 \\
\hline 960 & 1.14 & 1.17 & 1.21 & 1.24 & 1.30 & 1.14 & 1.17 & 1.21 & 1.25 & 1.30 \\
\hline 1020 & 1.14 & 1.24 & 1.24 & 1.25 & 1.30 & 1.14 & 1.24 & 1.25 & 1.24 & 1.24 \\
\hline$\geq 1080$ & 1.12 & 1.13 & 1.14 & 1.14 & 1.14 & 1.13 & 1.15 & 1.14 & 1.15 & 1.20 \\
\hline
\end{tabular}
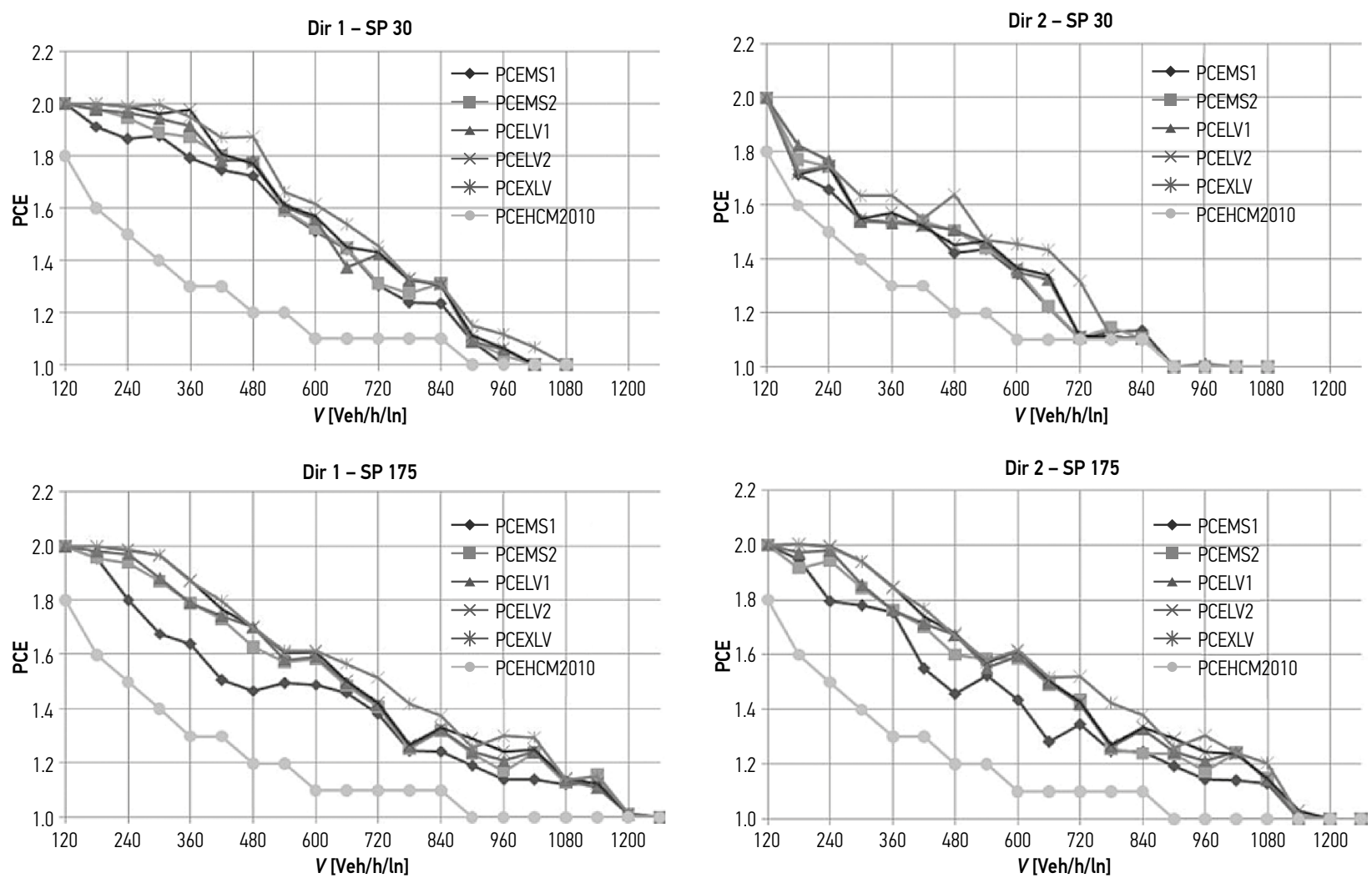

Fig. 4. PCE for different 'traffic volume' classes

'flow rate' through the PCE coefficients discussed in the previous chapter.

It has been observed that experimental data are well interpreted by the Greenshield model for roads with an uninterrupted flow. This model predicts, of course, a linear ' $S-D$ ' (De Luca, Dell'Acqua 2012) relation and a parabolic ' $V-D$ ' and ' $V-S$ ' relation. In particular, to determine the relationship between the three 'traffic flow' parameters, the following procedures were used:

- to construct the diagram ' $V-S$ ', flow classes $V$ were constructed with an range of $60 \mathrm{pcphpl}$ and the average speed was determined for each class. 
- to construct diagram ' $V-D$ ', classes of flow $V$ were constructed, with a width of $60 \mathrm{pcphpl}$, and for each class the average vehicle density was determined.

- to construct diagram ' $S-D$ ', classes of density, $D$, with a width of $0.2 \mathrm{pc} / \mathrm{km} / \mathrm{ln}$ (passenger car per kilometer per lane) were constructed, and for each class, the average speed was determined (Dell'Acqua et al. 2011).

Again, given the large number of records analyzed (about 500000), it was necessary to construct the appropriate support procedures for performing calculations in a reasonable time. Figs 5 and 6 show the results obtained for the two different directions on the two roads analyzed (SP30 and SP175). From the flow diagrams obtained experimentally, there are speeds (defined as the critical speed) close to $50 \div 55 \mathrm{~km} / \mathrm{h}$ (excluding the survey conducted on the SP175 for direction $d 2$, which is considerably higher). This speed, defined as 'critical speed', is the speed at which a heavy vehicle is equivalent to a car.
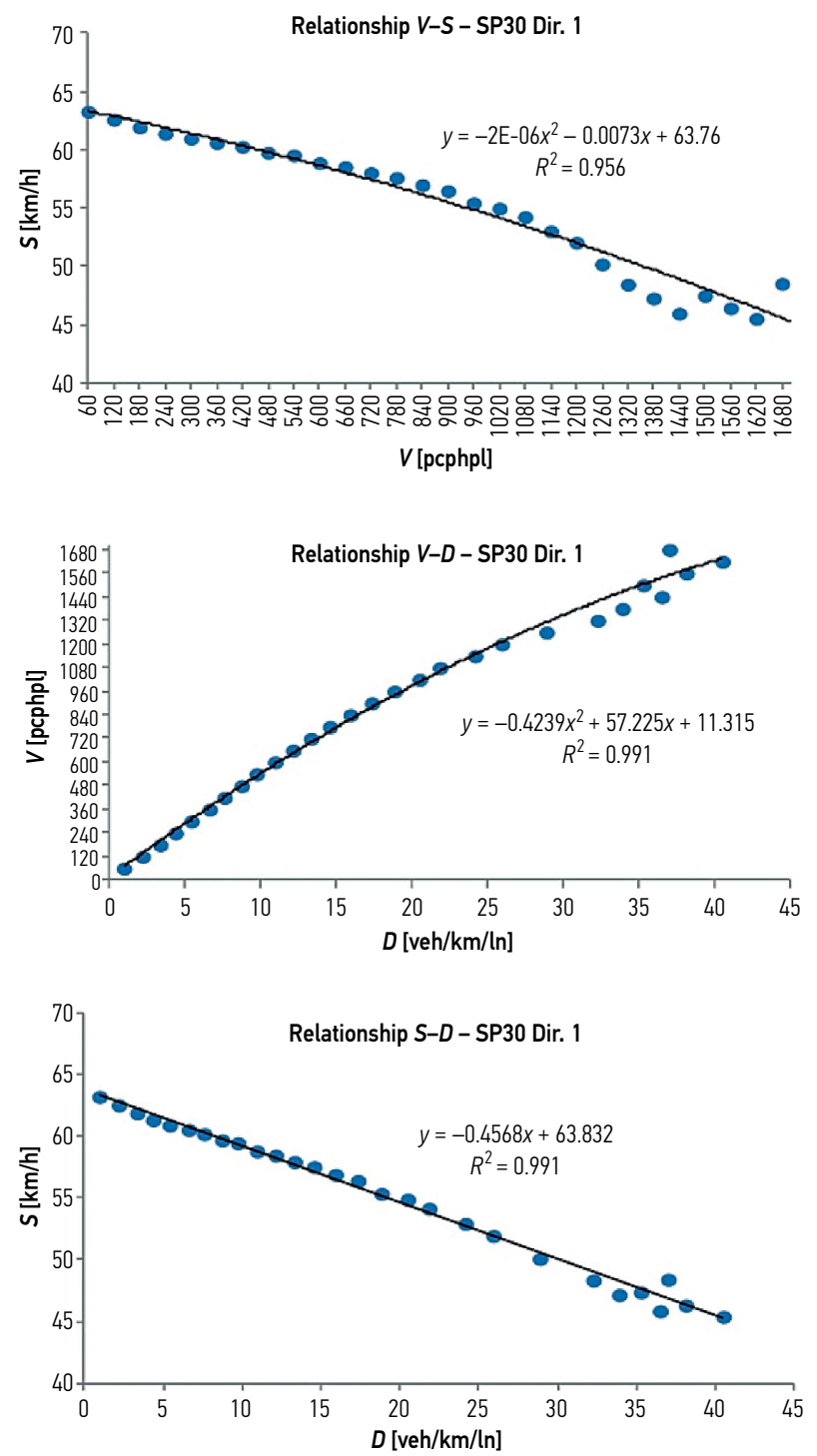

\section{Conclusions}

The method of calculating the LOS, and in particular of determining the PCE coefficients proposed by the Highway Capacity Manual, is based mainly on studies and research developed in the USA. To transfer this method to another reality (for example, Italy), it is necessary to conduct evaluations locally. In this work a series of experimental studies were carried out to assess some of these procedures.

The data were collected using two fixed RTMS (Remote Traffic Microwave Sensor) devices measuring traffic flow in two sections located at $3100 \mathrm{~km}$ on the SP30 and $8900 \mathrm{~km}$ on the SP175, from 1 January to $31 \mathrm{De}$ cember 2010.

The PCE coefficients were determined together with the relationship between the fundamental parameters of traffic flow ( $V, S$ and $D$ ) using the procedures set out in the Highway Capacity Manual (2010). Using the data, it has been possible to obtain not only the relations
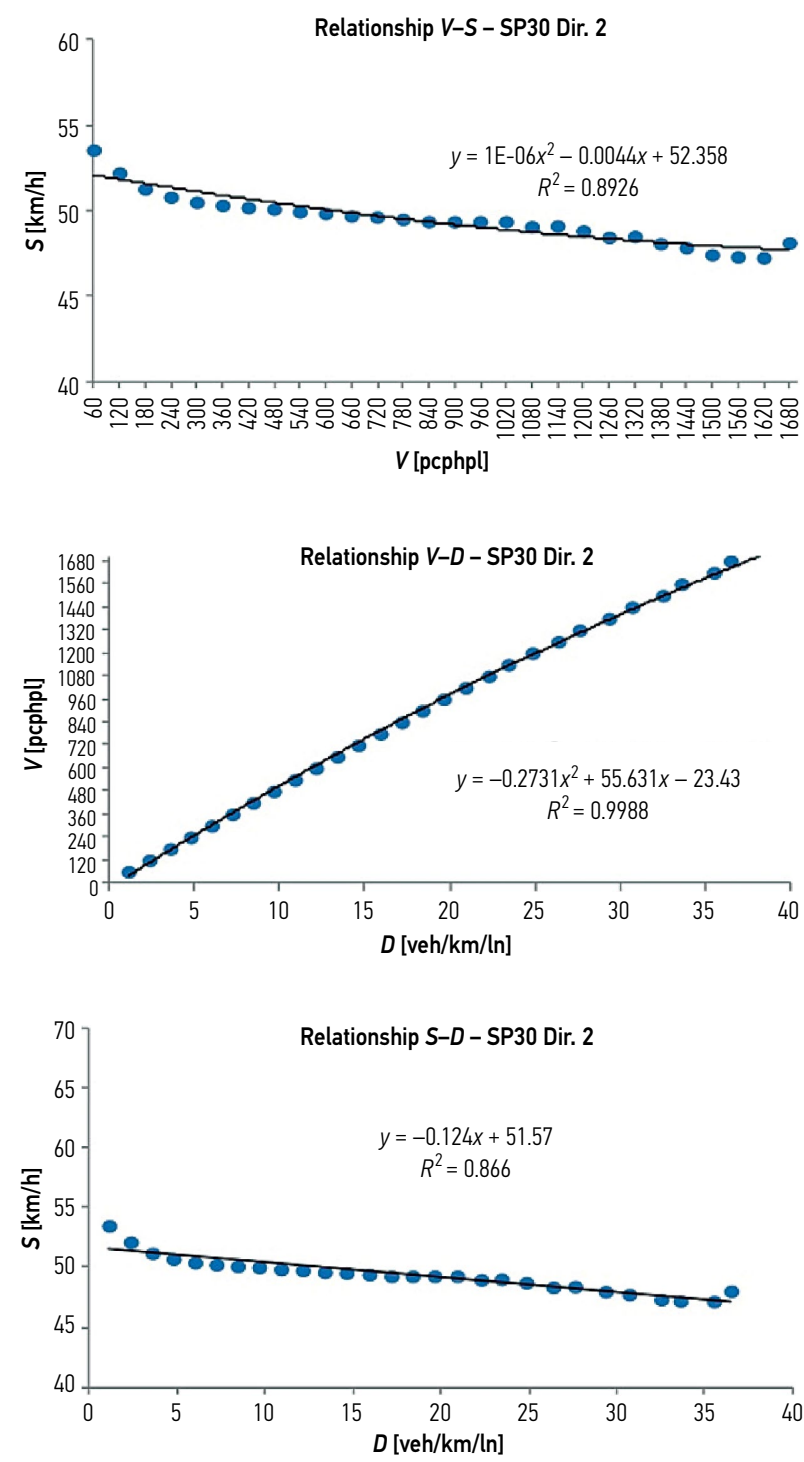

Fig. 5. Relationship between $S, V$ and $D$ for SP30 road 

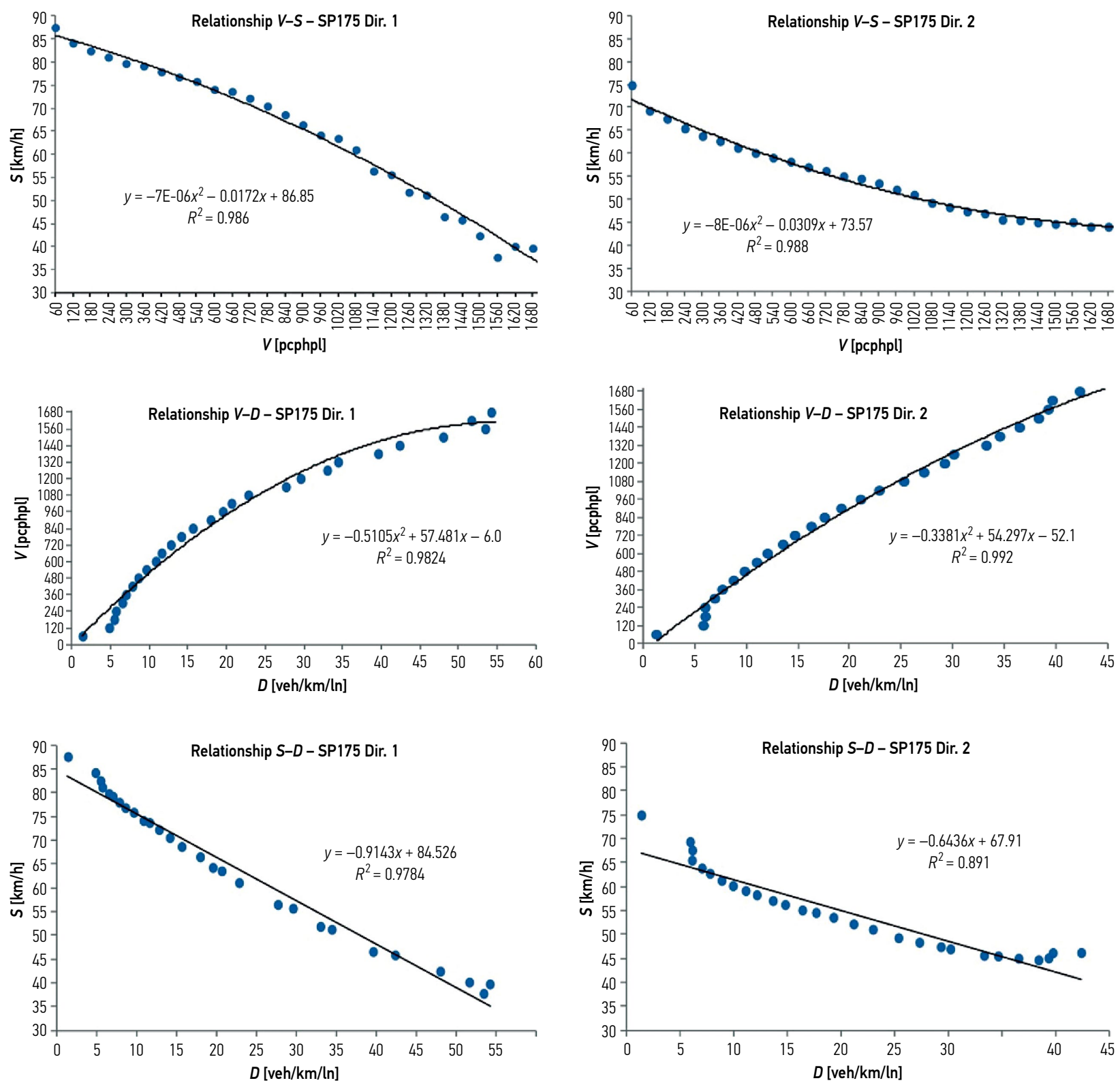

Fig. 6. Relationship between $S, V$ and $D$ for SP175 road

between the basic parameters of the flow, but also the PCE values in some traffic conditions.

The results showed that while the PCE analyzed have the same range as recorded in the Highway Capacity Manual (2010) - values between 1 and 2 - they are on average greater than those indicated by the manual, with a difference that tends to diminish beyond a flow rate of $400 \div 450 \mathrm{veh} / \mathrm{h} / \mathrm{pl}$ (Fig. 4). Furthermore, the PCE coefficients tend towards 1 (i.e. the condition in which a heavy vehicle is comparable to a car) for flow values approaching $1000 \mathrm{pcphpl}$; for these values, as may be seen from this first analysis, carried out under these traffic conditions, it can be concluded that, in terms of size and performance, PCE values, while varying within the same range indicated in the Highway Capacity Manual (2010), are generally higher and tend to 1 for values higher than the flow rate.
Furthermore, the relationship between the runoff values $(V, D, S)$ were in line with the contents of the Highway Capacity Manual (2010); in particular it was found that the experimental data analyzed are well interpreted by the Greenshield model for roads with an uninterrupted flow. To consolidate these results, the research is proceeding with other experimental studies concerning different infrastructures on which tests are being carried out also in different traffic conditions.

\section{References}

Al-Kaisy, A. F.; Hall, F. L.; Reisman, E. S. 2002. Developing passenger car equivalents for heavy vehicles on freeways during queue discharge flow, Transportation Research Part A: Policy and Practice 36(8): 725-742.

http://dx.doi.org/10.1016/S0965-8564(01)00032-5 
Chandra, S.; Kumar, V.; Sikdar, P. K. 1995. Dynamic PCU and estimation of capacity of urban roads, Indian Highways 23(4): 17-28.

Cunagin, W. D.; Messer, C. J. 1983. Passenger-car equivalents for rural highways, Transportation Research Record 905: $61-68$.

Cunha, A. L.; Setti, J. R. 2011. Truck equivalence factors for divided, multilane highways in Brazil, Procedia - Social and Behavioral Sciences 16: 248-258.

http://dx.doi.org/10.1016/j.sbspro.2011.04.447

Dell'Acqua, G.; De Luca, M.; Mauro, R.; Lamberti, R. 2011. Motorway speed management in Southern Italy, Procedia Social and Behavioral Sciences 20: 49-58. http://dx.doi.org/10.1016/j.sbspro.2011.08.010

De Luca, M.; Dell'Acqua, G. 2012. Freeway safety management: case studies in Italy, Transport 27(3): 320-326. http://dx.doi.org/10.3846/16484142.2012.724447

Elefteriadou, L.; Torbic, D.; Webster, N. 1997. Development of passenger car equivalents for freeways, two-lane highways, and arterials, Transportation Research Record 1572: 51-58. http://dx.doi.org/10.3141/1572-07

Fan, H. S. L. 1990. Passenger car equivalents for vehicles on Singapore expressways, Transportation Research Part A: General 24(5): 391-396. http://dx.doi.org/10.1016/0191-2607(90)90051-7

Highway Capacity Manual. 2010. Transportation Research Board. 5th edition. $1650 \mathrm{p}$.

Huber, M. J. 1982. Estimation of passenger-car equivalents of trucks in traffic stream, Transportation Research Record 869: 60-70.

Krammes, R. A.; Crowley, K. W. 1986. Passenger car equivalents for trucks on level freeway segments, Transportation Research Record 1091: 10-17.

Linzer, E. M.; Roess, R. P.; McShane, W. R. 1979. Effect of trucks, buses, and recreational vehicles on freeway capacity and service volume, Transportation Research Record 699: $17-26$.

Sun, D.; Lv, J.; Paul, L. 2008. Calibrating passenger car equivalent (PCE) for highway work zones using speed and percentage of trucks, in TRB 87th Annual Meeting Compendium of Papers DVD, 13-17 January 2008, Washington, DC. 18 p. (DVD).

Van Aerde, M.; Yagar, S. 1984. Capacity, speed, and platooning vehicle equivalents for two-lane rural highways, Transportation Research Record 971: 58-67.

Webster, N.; Elefteriadou, L. 1999. A simulation study of truck passenger car equivalents (PCE) on basic freeway sections, Transportation Research Part B: Methodological 33(5): 323336. http://dx.doi.org/10.1016/S0965-8564(98)00036-6

Werner, A.; Morrall, J. F. 1976. Passenger car equivalencies of trucks, buses, and recreational vehicles for two-lane rural highways, Transportation Research Record 615: 10-17. 